\title{
Complementary and alternative medicine use among infertile women attending infertility specialty clinics in South Korea: does perceived severity matter?
}

\author{
Jung Hye Hwang ${ }^{1,2,3}$, Yi Young Kim ${ }^{4}$, Hyea Bin $\mathrm{Im}^{2,3}$ and Dongwoon $\mathrm{Han}^{2,3,4,5^{*}}$
}

\begin{abstract}
Background: Complementary and alternative medicine (CAM) use among infertile women is popular in many countries, including Korea. Previous research has repeatedly found more than half of infertile women surveyed use CAM therapies for fertility enhancement and overall well-being. However, there is currently little evidence to support this practice, and this raises the question of infertile women's experiences in the uptake of those modalities and sociodemographic and psychological factors associated with CAM use. Thus, this study aims to explore the perceptions and experiences of infertile women with regard to their use of CAM in Korea.

Methods: A cross-sectional study was conducted using data from 263 infertile women attending infertility specialty clinics in Seoul, Korea, in June 2012. The survey instrument included 47 questions on the use of CAM, demographic characteristics, health status, and infertility related factors such as duration and type of infertility, experience and satisfaction of conventional treatment, and self-perceived severity of infertility condition. Chi-square test and logistic regression were used for data analysis.
\end{abstract}

Results: Among 286 respondents (response rate, 95.3\%), a total of 263 women were included in the final analysis. 63.5\% of respondents used one or more types of CAM modalities during infertility treatment. The utilization of CAM was associated with employment status, duration of infertility treatment, and self-perceived severity of the disease. The most commonly used CAM modalities were multivitamin and herbal medicine, and differences in types of CAM modalities used were found between the group with a higher rating of self-perceived disease severity and the lower perceived severity group.

Conclusions: High prevalence of CAM use among infertile women was observed in Korea. Our findings support that infertile women's own understanding of their illness and physical condition influences self-care behavior such as CAM use. This calls for an urgent need for further in-depth study of the clinical effects of popular CAM modalities among infertile women when used in conjunction with conventional treatment.

Keywords: Infertility, Reproductive health, Complementary and alternative medicine, Perceived severity of illness, Korea

\footnotetext{
* Correspondence: dwhan@hanyang.ac.kr

2Department of Global Health and Development, Graduate school, Hanyang

University, Seoul, South Korea

${ }^{3}$ Institute of Health Services Management, Hanyang University, Seoul, South

Korea

Full list of author information is available at the end of the article
}

(c) The Author(s). 2019 Open Access This article is distributed under the terms of the Creative Commons Attribution 4.0 International License (http://creativecommons.org/licenses/by/4.0/) which permits unrestricted use, distribution, and reproduction in any medium, provided you give appropriate credit to the original author(s) and the source, provide a link to the Creative Commons license, and indicate if changes were made. The Creative Commons Public Domain Dedication waiver (http://creativecommons.org/publicdomain/zero/1.0/) applies to the data made available in this article, unless otherwise stated. 


\section{Background}

Complementary and alternative medicine (CAM) refers to a group of non-mainstream healthcare systems, practices, and products used either in conjunction with or in place of conventional medicine [1]. According to National Center for Complementary and Integrative Health $(\mathrm{NCCIH}), \mathrm{CAM}$ modalities are categorized into three major groups: natural products, mind and body practices, and other complementary health approaches [1], but detailed categorization can vary depending on sociocultural background [2, 3]. A high prevalence of CAM use is especially seen in the reproductive age group $[4,5]$, where their main purpose of CAM use is for pregnancy-related health issues due to the perceptions that CAM modalities are safer, more natural, and holistic approach to health [6-9].

Among reproductive health concerns, infertility in particular, is a multifactorial chronic condition which affects 48.5 million couples worldwide [10]. The condition negatively affects physical, mental, and even social aspects of women in both developing and developed countries due to various factors such as late marriage, stress, obesity, long-term use of birth control, and pollution, yet it has not been receiving much attention [4, 11-17]. Korean women are also faced with challenges due to fertility-related issues: based on available data, $13.5 \%$ of women between the ages of 15 to 39 suffer from infertility [18], and $94.6 \%$ of those women suffer from depression. $26.6 \%$ of working women quit their jobs, and $8.9 \%$ take career-breaks to continue to receive infertility treatment [14]. For such reasons, infertility poses a great public health concern requiring an appropriate response plan.

It has been speculated that infertile women use CAM frequently in addition to conventional therapy not only to increase the chances of conception, but also to alleviate psychological, clinical, and physical concerns arising from being infertile and under various clinical treatments $[4,6,7,12,19]$. Although there is little evidence to support this practice, current international research suggests that $29-96 \%$ of infertile women seek CAM in addition to conventional therapies [11-13, 19-26], and this raises the question of infertile women's experiences in uptake of these modalities, as well as sociodemographic and psychological factors associated with CAM use.

Nevertheless, even with such widespread use of CAM modalities, only a few studies have examined the pattern of CAM use among infertile women in Asian countries [27]. Furthermore, existing literature mainly focuses on examining the characteristics of CAM users, preferred modalities, source of information, and disclosure to the physician(s) [4]. A few studies have identified certain sociodemographic characteristics and health and illness- related characteristics to be correlated with CAM use $[11,12,19,28]$.

Among the factors associated with CAM uptake, we specifically focused on the self-perceived severity of the disease, a component of the Health Belief Model constructed by Rosenstock et al. [29]. Prior studies on chronic disease patients found a greater perception of disease severity to be associated with CAM use [30, 31], and other studies on women with reproductive concerns also found perceived symptom severity to be potential predictors of CAM use [32, 33]. Infertility also being a chronic condition [34] that requires relatively longer treatment duration, close monitoring, and continuous follow up of disease condition, we hypothesized that infertile women's self-perceived severity of their condition to be associated with CAM use. Also, we speculated that differences would be found in the pattern of CAM use and clinical characteristics of infertile women with a greater perception of disease severity.

Hence, the aim of this study was not only to investigate general characteristics, but also to examine factors associated with CAM use among infertile women attending specialized infertility clinics in South Korea. Lastly, we examined differences in clinical, subjective well-being, and characteristics related to CAM use between women with a higher rating of self-perceived disease severity and those with a lower rating of disease severity.

\section{Methods}

\section{Study setting and participants}

This research was a descriptive cross-sectional in design, conducted at three specialized infertility clinics located in Seoul, South Korea. All infertile women visiting the clinics were eligible to take part in the survey. Exclusion criteria were women who were pregnant at the time of the survey and unable to speak or mentally unstable.

The sample size for this study was calculated using the formula for sample size determination using confidence interval (CI) of proportion: $n=z_{\alpha / 2}^{2} \cdot \frac{p q}{d^{2}}$. To determine the required sample size (n), the margin of error (d) was set on 0.06 , and the estimated proportion of CAM use among infertile women (p) was calculated using the data from previous studies conducted in Korea (0.669) [35-37]. q is the proportion of people not using CAM (1-p), and $z_{0.025}$ is 1.96 , which corresponds to a confidence interval of $95 \%$. This equation gave the minimum sample size as 236 participants, and we distributed a total of 300 survey questionnaires assuming $20 \%$ non-response rate.

\section{Survey instrument}

After reviewing the literature $[6,11,21]$, the survey questionnaire was developed in the Korean language. In 
order to examine content and face validation of the survey instrument, the questionnaire was reviewed by three researchers to assess the relevancy, organization, appropriateness, rationality, and clarity of the questions. A pilot study was also conducted on a sample of 20 participants to evaluate readability and ambiguities, and a few items were revised based on the results. The final version of the questionnaire consisted of 47 items, with both multiple-choice and open-ended questions, and respondents' perceptions and attitudes were measured using a 5-point Likert scale.

The questionnaire consisted of four major sections. The first section had 14 questions concerning the respondents' health status, the practice of health-promoting behavior [(practicing healthy diet, regular exercise, and adequate sleep $(1=$ never, $5=$ very well $)]$, presence of comorbidities, infertility related characteristics, gravidity, self-perceived severity of infertility condition $(1=$ not at all, $5=$ very much), and the level of psychological stress (pressure and anxiety) due to infertility ( $1=$ not at all, $5=$ very much $)$. The second section contained eight questions regarding patterns of health service use, satisfaction with infertility treatment, the experience of adverse reaction to conventional infertility treatment, and infertility treatmentrelated cost.

The third section included 18 questions on CAM use. The first question asked, "Did you use any CAM during the last 12 months?" and the CAM users were asked to check which modalities were used from the list provided in the survey. The respondents who reported using at least one CAM modality were also asked about patterns of CAM use, reasons for use, perceived health benefits of CAM use, satisfaction with CAM, respondent's attitudes and beliefs toward CAM, and source of information on CAM. The last section comprised of seven questions on participants' age, level of income, level of education, occupation, and area of residence.

\section{Data collection}

For this study, ethical approval of the study was obtained from the Institutional Review Board on Human Subjects Research and Ethics Committees, Hanyang University (HYI-12-019). Three surveyors were trained and recruited for data collection. Information about the research was given verbally to each respondent, and prior to the survey, all participants completed IRB-approved written informed consent. Participants were informed that they could quit the survey anytime they wanted to, and the respondents were asked to fill out the questionnaire themselves. A total of 300 survey questionnaires were distributed, but 14 participants did not return or complete the questionnaire (response rate: 95.3\%). The data of 23 women who were pregnant at the time were also excluded from data analysis; therefore, the data of
263 respondents were included in the final analysis. The survey was conducted for eight days (starting from June 7th, 2012).

\section{Statistical analysis}

The collected data of 263 were entered in Microsoft Excel and were analyzed using the software Statistical Package for Social Sciences (SPSS) v. 21. Descriptive statistics were used to describe sociodemographic and reproductive health-related characteristics of study respondents. Pearson's Chi-square test and Fisher's exact test were executed to identify differences in sociodemographic (age, education level, household income, religious affiliation, and employment status) and reproductive health-related characteristics (type of infertility, treatment duration, infertility diagnosis, type of current treatment, level of self-practice of health-promoting behavior, self-perceived stress and severity, effectiveness of conventional treatment, presence of comorbidity, and experiences of adverse reaction to conventional treatment) between users and non-users of CAM.

Also, to examine variations in types of CAM modalities used according to the perceived severity of infertility, we divided the respondents into two groups: severe and non-severe group based on self-rating of the severity of the disease. The high perceived disease severity group includes women who rated their severity as 4 or 5 on a 5 -point Likert scale; the low perceived severity group includes women who rated the severity from 1 to 3 . For data analysis, the categorization of CAM types was done by the National Center for Complementary and Integrative Health $(\mathrm{NCCIH})$ domain: natural products, mind and body practices, and other complementary health approaches. However, all practices prescribed or performed by traditional Korean medicine doctors were classified as "other complementary health approaches." Chi-square test was then performed to investigate differences in types of CAM modalities used based on selfrating of the severity of the disease.

Lastly, to examine potential factors associated with CAM use, significant factors from previous chi-square test (employment status, treatment duration, degree of the practice of health-promoting behavior, self-perceived severity of illness, the experience of adverse reaction to conventional treatment) were selected to be analyzed using a multivariate regression model. A $P$-value of less than 0.05 was considered statistically significant for all analyses.

\section{Results}

\section{Sociodemographic characteristics of study participants}

The sociodemographic characteristics of the study participants are presented in Table 1 . The mean age of respondents was 34.4 years old $(\mathrm{SD}=4.22)$. The majority were $30-39$ years of age $(76.8 \%)$, had higher than or 
Table 1 Sociodemographic characteristics of participants

\begin{tabular}{|c|c|c|c|c|}
\hline Characteristics & $\begin{array}{l}\text { Overall } \\
n=263(\%)\end{array}$ & $\begin{array}{l}\text { CAM users } \\
n=167(\%)\end{array}$ & $\begin{array}{l}\text { Non-users } \\
n=96(\%)\end{array}$ & $P$-value \\
\hline Mean age (years) & $34.4 \pm 4.22$ & $34.5 \pm 4.19$ & $34.2 \pm 4.30$ & \\
\hline$<30$ & $30(11.4)$ & $20(12.0)$ & $10(10.4)$ & $0.756^{\mathrm{a}}$ \\
\hline $30-34$ & $112(42.6)$ & $67(40.1)$ & $45(46.9)$ & \\
\hline $35-39$ & $90(34.2)$ & $59(35.3)$ & $31(32.3)$ & \\
\hline$\geq 40$ & $31(11.7)$ & $21(12.6)$ & $11(10.4)$ & \\
\hline \multicolumn{5}{|l|}{ Education level } \\
\hline$\leq$ Secondary & $30(11.4)$ & $19(11.4)$ & $11(11.5)$ & $0.984^{a}$ \\
\hline$\geq$ University level & 233 (88.6) & 148 (88.6) & $85(88.5)$ & \\
\hline \multicolumn{5}{|l|}{ Household income } \\
\hline$<300$ million KRW & $51(19.4)$ & $34(20.4)$ & $17(17.7)$ & $0.569^{\mathrm{a}}$ \\
\hline 300-500 million KRW & $116(44.1)$ & $76(45.5)$ & $40(41.7)$ & \\
\hline$\geq 500$ million KRW & $96(36.5)$ & $57(34.1)$ & $39(40.6)$ & \\
\hline \multicolumn{5}{|l|}{ Religious affiliation } \\
\hline Yes & $179(68.1)$ & $118(70.7)$ & $61(63.5)$ & $0.307^{\mathrm{a}}$ \\
\hline No & $84(31.9)$ & $49(29.3)$ & $35(36.5)$ & \\
\hline \multicolumn{5}{|l|}{ Employment status } \\
\hline Yes & $143(54.4)$ & $81(48.5)$ & $62(64.6)$ & $0.012^{a}$ \\
\hline No & $120(45.6)$ & $86(51.5)$ & $34(35.4)$ & \\
\hline
\end{tabular}

CAM Complementary and Alternative Medicine

${ }^{\text {a }}$ Denotes Pearson's Chi-square tests

equal to university education (88.6\%), had a household income greater than 3 million KRW per month (57.1\%), and were employed (54.4\%). The proportion of employed women was significantly higher in the nonCAM user group $(p=0.012)$.

\section{Infertility characteristics of study participants}

Table 2 shows the fertility-related characteristics of the study participants. The majority of respondents suffered from primary infertility (53.2\%). $65.4 \%$ of respondents had been under infertility treatment for less than 2 years, and the difference in treatment duration between CAM user and non-user groups was statistically significant $(p=0.010)$. Female infertility was the most common diagnosis (27.0\%), and $54.4 \%$ of respondents were under the IVF treatment.

\section{Health-related characteristics of respondents}

Health-related characteristics of the study participants are demonstrated in Table 3. The average score of healthpromoting behavior (practicing a healthy diet, regular exercise, and adequate sleep) in the CAM user group was significantly greater than that of non-users $(p=0.025)$. The majority of respondents $(81.4 \%)$ did not suffer from other comorbidities, and the mean score of the selfperceived severity was significantly higher among CAM users $(p=0.009)$. The respondents rated their selfperceived effectiveness of conventional treatment and
Table 2 Fertility-related characteristics of participants

\begin{tabular}{|c|c|c|c|c|}
\hline Characteristics & $\begin{array}{l}\text { Total } \\
n=263 \\
(\%)\end{array}$ & $\begin{array}{l}\text { CAM users } \\
n=167 \\
(\%)\end{array}$ & $\begin{array}{l}\text { Non- } \\
\text { users } \\
n=96 \\
(\%)\end{array}$ & $P$-value \\
\hline \multicolumn{5}{|l|}{ Type of infertility } \\
\hline $1^{\circ}$ infertility & $140(53.2)$ & $88(52.7)$ & $52(54.2)$ & \multirow[t]{2}{*}{$0.351^{a}$} \\
\hline $2^{\circ}$ infertility & $123(46.8)$ & $79(47.3)$ & $44(45.8)$ & \\
\hline \multicolumn{5}{|l|}{ Infertility treatment duration } \\
\hline$<2$ years & $172(65.4)$ & $101(60.5)$ & $71(74.0)$ & \multirow[t]{3}{*}{$0.010^{\mathrm{a}}$} \\
\hline 2-4 years & $57(21.7)$ & $46(27.5)$ & $11(11.5)$ & \\
\hline$>4$ years & $34(12.9)$ & $20(12.0)$ & $14(14.6)$ & \\
\hline \multicolumn{5}{|l|}{ Infertility diagnosis } \\
\hline Female factor only & $71(27.0)$ & $47(28.1)$ & $24(25.0)$ & \multirow[t]{6}{*}{$0.759^{b}$} \\
\hline Male factor only & $22(8.4)$ & $14(8.4)$ & $8(8.3)$ & \\
\hline Male and female factors & $15(5.7)$ & $10(6.0)$ & $5(5.2)$ & \\
\hline Don't know & $50(19.0)$ & $28(16.8)$ & $22(22.9)$ & \\
\hline Unknown (not identified) & $95(36.1)$ & $63(37.7)$ & $32(33.3)$ & \\
\hline Others & $10(3.8)$ & $5(3.0)$ & $5(5.2)$ & \\
\hline \multicolumn{5}{|l|}{ Type of treatment } \\
\hline Non-IVF treatment & $120(45.6)$ & $73(43.7)$ & $47(49.0)$ & \multirow[t]{2}{*}{$0.411^{\mathrm{a}}$} \\
\hline IVF treatment & $143(54.4)$ & $94(56.3)$ & $49(51.0)$ & \\
\hline
\end{tabular}

CAM Complementary and Alternative Medicine

${ }^{a}$ Denotes Pearson's Chi-square tests

${ }^{\mathrm{b}}$ Denotes Fisher's exact test

their satisfaction level as $3.54(\mathrm{SD}=0.69)$ and $3.59(\mathrm{SD}=$ 0.63 ), respectively. $75.7 \%$ of respondents had no experience of adverse reaction to conventional infertility treatment; however, the proportion of women who experienced an adverse reaction to conventional treatment was greater in the CAM user group $(p=0.028)$.

\section{CAM modalities used based on the perception of disease severity}

Table 4 presents the CAM modalities used by respondents based on the self-rating of disease severity. Among natural products, multivitamin was most used modality (84.4\%) followed by Korean black raspberry (Rubus coreanus). Consumption of multivitamin $(p=0.043)$, Korean black raspberry $(p=0.008)$, ginseng and red ginseng $(p<0.001)$, blood circulation supplement pills $(p=$ $0.006)$, and herbal tea $(p=0.013)$ was significantly greater in the group with a higher rating of disease severity. For mind and body practices, practice of lower body and hot spring bath, yoga, and pray/meditation was most common among respondents $(31.7,25.9,15.6 \%$ respectively), and it was also found that practice of lower body and hot spring bath $(p=0.028)$ was significantly higher in the group with the greater perception of disease severity. Among traditional Korean medicine approaches, consumption of herbal medicine was most 
Table 3 Health-related characteristics of respondents $(n=263)$

\begin{tabular}{lllll}
\hline Characteristics & $\begin{array}{l}\text { Overall } \\
n=263(\%)\end{array}$ & $\begin{array}{l}\text { CAM users } \\
n=167(\%)\end{array}$ & $\begin{array}{l}\text { Non-users } \\
n=96(\%)\end{array}$ & P-value \\
\hline $\begin{array}{l}\text { Practice of health- } \\
\text { promoting behavior } \\
\text { (Mean } \pm \text { SD) }\end{array}$ & $3.02 \pm 0.68$ & $3.10 \pm 0.65$ & $2.86 \pm 0.72$ & \\
Yes $(4,5)$ & $52(19.8)$ & $40(24.0)$ & $12(12.5)$ & 0.025 \\
No $(1,2,3)$ & $211(80.2)$ & $127(76.0)$ & $84(87.5)$ &
\end{tabular}

Presence of

comorbidity

\begin{tabular}{|c|c|c|c|c|}
\hline Yes & 49 (18.6) & $32(19.2)$ & $17(17.7)$ & $0.870^{\mathrm{a}}$ \\
\hline No & $214(81.4)$ & $135(80.8)$ & 79 (82.3) & \\
\hline $\begin{array}{l}\text { Self-perceived } \\
\text { stress (Mean } \pm \text { SD)* }\end{array}$ & $3.77 \pm 0.83$ & $3.85 \pm 0.81$ & $3.64 \pm 0.86$ & \\
\hline Severe $(4,5)$ & $158(60.1)$ & $107(64.1)$ & $51(53.1)$ & $0.081^{\mathrm{a}}$ \\
\hline Not severe $(1,2,3)$ & $105(39.9)$ & $60(35.9)$ & $45(46.9)$ & \\
\hline $\begin{array}{l}\text { Self-perceived } \\
\text { severity of their } \\
\text { condition } \\
(\text { Mean } \pm \text { SD) }\end{array}$ & $3.72 \pm 0.90$ & $3.78 \pm 0.84$ & $3.61 \pm 0.98$ & \\
\hline Not severe $(1,2,3)$ & $105(39.9)$ & $57(34.1)$ & $48(50.0)$ & $0.009^{a}$ \\
\hline Severe (4) & $105(39.9)$ & $78(46.7)$ & $27(28.1)$ & \\
\hline Very severe (5) & $53(20.2)$ & $32(19.2)$ & $21(21.9)$ & \\
\hline $\begin{array}{l}\text { Self-perceived } \\
\text { effectiveness of } \\
\text { conventional } \\
\text { treatment } \\
\left(\text { Mean } \pm \text { SD) }{ }^{1}\right.\end{array}$ & $3.54 \pm 0.69$ & $3.51 \pm 0.65$ & $3.60 \pm 0.76$ & \\
\hline Effective $(4,5)$ & $134(51.0)$ & $83(49.7)$ & $51(53.1)$ & $0.593^{\mathrm{a}}$ \\
\hline Ineffective $(1,2,3)$ & $129(49.0)$ & $84(50.3)$ & $45(46.9)$ & \\
\hline $\begin{array}{l}\text { Satisfaction level } \\
\text { of conventional } \\
\text { treatment } \\
(\text { Mean } \pm S D)^{2}\end{array}$ & $3.59 \pm 0.63$ & $3.56 \pm 0.60$ & $3.63 \pm 0.68$ & \\
\hline Satisfied $(4,5)$ & $147(55.9)$ & $91(54.5)$ & $56(58.3)$ & $0.546^{\mathrm{a}}$ \\
\hline Dissatisfied $(1,2,3)$ & $116(44.1)$ & $76(45.5)$ & $40(41.7)$ & \\
\hline \multicolumn{5}{|l|}{$\begin{array}{l}\text { Experience of adverse } \\
\text { reaction to } \\
\text { conventional } \\
\text { treatment }\end{array}$} \\
\hline Yes & $64(24.3)$ & $48(28.7)$ & $16(16.7)$ & $0.028^{a}$ \\
\hline No & $199(75.7)$ & $119(71.3)$ & $80(83.3)$ & \\
\hline
\end{tabular}

\# Participants were asked to rate their practice of health-promoting behavior (practicing a healthy diet, regular exercise, and adequate sleep)

( $1=$ Never, 5 = Always)

*Participants were asked to rate their self-perceived stress level $(1=$ Not at all, $5=$ Very much)

'Participants were asked to rate their self-perceived severity of infertility condition ( $1=$ Not at all, $5=$ Very much)

${ }^{1}$ Participants were asked to rate their self-perceived effectiveness of conventional treatment ( $1=$ Not at all, $5=$ Very much)

${ }^{2}$ Respondents were asked to rate their satisfaction to conventional fertility treatment $(1=$ Very dissatisfied, $5=$ Very satisfied)

${ }^{a}$ Denotes Pearson's Chi-square tests

popular (72.5\%), followed by moxibustion (19.2\%), and a statistically significant difference was shown in the use of herbal medicine $(p=0.001)$.
Table 4 CAM modalities used by infertile women based on their perceived level of disease severity

\begin{tabular}{|c|c|c|c|c|}
\hline CAM modalities & $\begin{array}{l}\text { Overall } \\
n=167 \\
(\%)\end{array}$ & $\begin{array}{l}\text { High } \\
\text { perceived } \\
\text { severity }(4,5){ }^{\#} \\
n=110(\%)\end{array}$ & $\begin{array}{l}\text { Low } \\
\text { perceived } \\
\text { severity } \\
(1,2,3) \# \\
n=57(\%)\end{array}$ & $P$-value \\
\hline \multicolumn{5}{|l|}{ Natural Product* } \\
\hline $\begin{array}{l}\text { Multivitamin } \\
\text { (folic acid, iron } \\
\text { supplement, etc.) }\end{array}$ & $141(84.4)$ & $93(84.5)$ & $48(84.2)$ & $0.043^{\mathrm{a}}$ \\
\hline $\begin{array}{l}\text { Korean black } \\
\text { raspberry (Rubus } \\
\text { coreanus/Rubi } \\
\text { Fructus) }\end{array}$ & $74(44.3)$ & $54(49.1)$ & $20(35.1)$ & $0.008^{\mathrm{a}}$ \\
\hline $\begin{array}{l}\text { Ginseng and } \\
\text { red ginseng }\end{array}$ & $63(37.7)$ & $50(45.5)$ & $13(22.8)$ & $\begin{array}{l}<.001^{a} \\
\end{array}$ \\
\hline Mugwort & $36(21.6)$ & 26 (23.6) & $10(17.5)$ & $0.143^{\mathrm{a}}$ \\
\hline Brown rice & $46(27.5)$ & $30(27.3)$ & $16(28.1)$ & $0.509^{a}$ \\
\hline $\begin{array}{l}\text { Blood circulation } \\
\text { supplement pills }\end{array}$ & $15(9.0)$ & $14(12.7)$ & $1(1.8)$ & $0.006^{b}$ \\
\hline Herbal tea & $9(5.4)$ & $9(8.2)$ & $0(0.0)$ & $0.013^{b}$ \\
\hline \multicolumn{5}{|l|}{$\begin{array}{l}\text { Mind and body } \\
\text { practices* }\end{array}$} \\
\hline $\begin{array}{l}\text { Lower body } \\
\text { bath/ hot } \\
\text { spring bath }\end{array}$ & $53(31.7)$ & 39 (35.5) & $14(24.6)$ & $0.028^{a}$ \\
\hline Yoga & $45(25.9)$ & $31(28.2)$ & $14(24.6)$ & $0.242^{\mathrm{a}}$ \\
\hline Pray/meditation & $26(15.6)$ & $18(16.4)$ & $8(14.0)$ & $0.400^{\mathrm{a}}$ \\
\hline Psychotherapy & $6(3.6)$ & $6(5.5)$ & $0(0.0)$ & $0.084^{b}$ \\
\hline $\begin{array}{l}\text { Hypogastric } \\
\text { breathing }\end{array}$ & $4(2.4)$ & $1(0.9)$ & $3(5.3)$ & $0.305^{b}$ \\
\hline Chiropractic & $3(1.8)$ & $3(2.7)$ & $0(0.0)$ & $0.278^{b}$ \\
\hline Massage & $15(9.0)$ & $12(10.9)$ & $3(5.3)$ & $0.173^{b}$ \\
\hline Magnetic therapy & $3(1.8)$ & $1(0.9)$ & $2(3.5)$ & $0.566^{b}$ \\
\hline \multicolumn{5}{|l|}{$\begin{array}{l}\text { Other complementary } \\
\text { health approaches } \\
\text { (Korean traditional } \\
\text { medicine) }\end{array}$} \\
\hline Herbal medicine & $121(72.5)$ & $86(78.2)$ & $35(61.4)$ & $0.001^{\mathrm{a}}$ \\
\hline Moxibustion & $32(19.2)$ & $23(20.9)$ & $9(15.8)$ & $0.179^{a}$ \\
\hline Acupuncture & $23(13.8)$ & 18 (16.4) & $5(8.8)$ & $0.075^{b}$ \\
\hline Bee venom therapy & $8(4.8)$ & $6(5.5)$ & $2(3.5)$ & $0.483^{b}$ \\
\hline
\end{tabular}

* Columns do not add up to $100 \%$ due to use of multiple treatments

\# Perceived severity of disease was self-rated by participants on a 5-point Likert scale $(1=$ Not at all, $5=$ Very much). Those who rated their severity from 1 to 3 were categorized as 'low perceived severity' group, whereas those who scored from 4 to 5 were put in 'high perceived severity' group

a Denotes Pearson's Chi-square tests

${ }^{b}$ Denotes Fisher's exact test

\section{Clinical characteristics of respondents by perceived severity of the disease}

Clinical characteristics of respondents based on selfrating of the severity of the disease are shown in Table 5. The number of respondents with higher self-perceived stress was significantly greater in the high perceived 
Table 5 Clinical characteristics of respondents by perceived severity of disease $(n=263)$

\begin{tabular}{|c|c|c|c|c|}
\hline Characteristics & $\begin{array}{l}\text { Overall } \\
n=263(\%)\end{array}$ & $\begin{array}{l}\text { High } \\
\text { perceived } \\
\text { severity } \\
n=158(\%) \\
\end{array}$ & $\begin{array}{l}\text { Low } \\
\text { perceived } \\
\text { severity } \\
n=105 \text { (\%) }\end{array}$ & $P$-value \\
\hline $\begin{array}{l}\text { Self-perceived } \\
\text { stress (Mean } \pm S D)^{*}\end{array}$ & $3.77 \pm 0.83$ & $4.16 \pm 0.69$ & $3.18 \pm 0.68$ & \\
\hline Severe $(4,5)$ & $158(60.1)$ & $132(83.5)$ & $26(24.8)$ & $<0.001^{\mathrm{a}}$ \\
\hline Not severe $(1,2,3)$ & $105(39.9)$ & $26(16.5)$ & $79(75.2)$ & \\
\hline \multicolumn{5}{|c|}{ Infertility treatment duration } \\
\hline$<2$ years & $172(65.4)$ & $87(55.1)$ & $85(81.0)$ & $<0.001^{\mathrm{a}}$ \\
\hline $2-4$ years & $57(21.7)$ & $44(27.8)$ & $13(12.4)$ & \\
\hline$>4$ years & $34(12.9)$ & $27(17.1)$ & $7(6.7)$ & \\
\hline $\begin{array}{l}\text { Practice of health- } \\
\text { promoting } \\
\text { behavior } \\
(\text { Mean } \pm S D)^{\#}\end{array}$ & $3.02 \pm 0.68$ & $3.04 \pm 0.70$ & $2.98 \pm 0.65$ & \\
\hline Yes $(4,5)$ & $52(19.8)$ & $34(21.5)$ & $18(17.1)$ & $0.431^{a}$ \\
\hline No $(1,2,3)$ & $211(80.2)$ & $124(78.5)$ & $87(82.9)$ & \\
\hline \multicolumn{5}{|l|}{ Time since diagnosis } \\
\hline$<2$ years & $137(52.1)$ & $68(43.0)$ & $69(65.7)$ & $0.001^{\mathrm{a}}$ \\
\hline $2-4$ years & $69(26.2)$ & $50(31.6)$ & $19(18.1)$ & \\
\hline$>4$ years & $57(21.7)$ & $40(25.3)$ & $17(16.2)$ & \\
\hline
\end{tabular}

severity group $(p<0.001)$. The proportion of women with infertility treatment duration greater than 2 years was also significantly higher in the group with a greater perception of disease severity $(p<0.001)$. Furthermore, significant differences in the time since diagnosis of infertility were observed $(p=0.001)$, where $56.9 \%$ of women in high-perceived severity group have been diagnosed with infertility longer than 2 years while $34.3 \%$ of women in low perceived severity group had the diagnosis for greater than 2 years.

\section{Potential predictors of CAM use}

The result of multivariate logistic regression analysis is demonstrated in Table 6. From the multivariate model, non-employment (OR: 1.87, CI: 1.08-3.23), infertility treatment duration of $2-4$ years (OR: 2.31, CI: 1.07-4.97), and self-perception of their disease severity as severe (OR: 2.14, CI: 1.16-3.95) were associated with CAM use.

\section{Discussion}

This study explored the prevalence and determinants of CAM use among infertile women in South Korea. The findings of our study showed a high prevalence of CAM utilization by $63.5 \%$ of the participants. This usage was
Table 6 Multivariate logistic regression analysis between demographic, health behavior, and reproductive health-related factors and use of CAM

\begin{tabular}{|c|c|c|c|}
\hline Characteristics & OR & $95 \% \mathrm{Cl}$ & $P$-value \\
\hline \multicolumn{4}{|l|}{ Employment status } \\
\hline Yes & 1 & Ref & \\
\hline No & 1.87 & $1.08-3.23$ & 0.025 \\
\hline \multicolumn{4}{|c|}{ Infertility treatment duration } \\
\hline$<2$ years & 1 & Ref & \\
\hline $2-4$ years & 2.31 & $1.07-4.97$ & 0.033 \\
\hline$>4$ years & 0.90 & $0.40-2.01$ & 0.793 \\
\hline \multicolumn{4}{|c|}{ Practice of health-promoting behaviora } \\
\hline No $(1,2,3)$ & 1 & Ref & \\
\hline Yes $(4,5)$ & 2.02 & $0.96-4.24$ & 0.063 \\
\hline \multicolumn{4}{|c|}{ Self-perceived severity of their condition ${ }^{b}$} \\
\hline Not severe $(1,2,3)$ & 1 & Ref & \\
\hline Severe (4) & 2.14 & $1.16-3.95$ & 0.014 \\
\hline Very severe (5) & 0.93 & $0.45-1.96$ & 0.856 \\
\hline \multicolumn{4}{|c|}{ Experience of adverse reaction to conventional treatment } \\
\hline No & 1 & Ref & \\
\hline Yes & 0.64 & $0.33-1.25$ & 0.193 \\
\hline
\end{tabular}

aparticipants were asked to rate their practice of health-promoting behavior (practicing a healthy diet, regular exercise, and adequate sleep) ( $1=$ Never, 5 = Always)

barticipants were asked to rate their self-perceived severity of infertility condition ( $1=$ Not at all, $5=$ Very much)

higher compared to the reports in Ireland (46\%), Lebanon (41\%), the U.S. (29\%), and the U.K. (40\%), yet lower than the prevalence found in Uganda (76\%), Australia (66\%), Taiwan (96\%), and Turkey (82\%) [11-13, 20-25]. These variations in prevalence can be explained by different definitions of CAM among studies, increase in CAM use over time, and actual differences in CAM use among respondents due to various cultural and socio-demographic characteristics [2].

Among sociodemographic and health-related characteristics of participants, a higher proportion of nonemployed women were observed in the CAM user group, yet in contrast to earlier findings, no significant differences were found between CAM users and nonusers in education level and household income $[13,19]$. The proportion of infertile women with treatment duration longer than 2 years was significantly greater in the CAM user group, whereas the type of infertility and current treatment type did not differ between the two groups in our findings. Similar to a previous study, we found a higher proportion of women engaging in healthpromoting behavior such as the practice of a healthy diet, sufficient exercise, and adequate sleep in the CAM user group [11]. More women who have experienced an adverse reaction to conventional infertility treatment 
were in the CAM user group, which can be attributed to mistrust in conventional medicine [38].

Congruent with previous findings in Turkey and Australia, the most commonly used CAM modality was multivitamin and other dietary supplements, while physical therapies such as chiropractic and qigong exercises were the least favored modalities [4, 23-25]. Patterns of CAM use reflect socioeconomic, cultural practices and beliefs $[12,22,26]$, as indicated by the high prevalence of herbal medicine use (71.3\%) among Korean women in our study due to the popular use of traditional Korean medicine [39]. Similarly, due to easy accessibility and availability of traditional medicine, the prevalence of herbal medicine use among Taiwanese infertile women was 96\% [24], whereas the prevalence was lower in Middle Eastern countries such as Turkey (29.3\%) and Lebanon $(43.5 \%)[12,25]$. The popularity of herbal medicine use was also lower in western countries such as the U.S. (16\%), Australia (29\%), and Ireland (46\%) [11, 20, 23]. However, in the Middle East, where religion is an essential part of their daily lives, a high prevalence of religious intervention was observed [12, 22, 25].

Among natural CAM products, other than a multivitamin, Korean black raspberry, also known as Rubi Fructus or Rubus coreanus, was found to be the most popular product among infertile women in Korea. In Donguibogam, a seventeenth-century Korean medical textbook upon which Traditional Korean Medicine has developed, Korean black raspberry is described as being effective in increasing male stamina and treating female infertility [40]. Based on this ancient tradition and cultural belief, it was observed that $44.3 \%$ of the respondents in our study had consumed Korean black raspberry to increase the chances of conception. This finding is particularly important as it demonstrates an example of popular use of non-evidence based medicine without proper physician consultation, and this calls for an immediate response plan as unsupervised use of traditional modalities may cause adverse effects when concurrently used with conventional medicine.

We further analyzed types of CAM modalities used depending on the level of self-rated disease severity, as it was found to be associated with CAM use in our study. Previous studies on women with reproductive concerns have found perceived symptom severity to be associated with CAM use $[32,33]$, yet no study has identified differences in the pattern of CAM use and clinical characteristics of infertile women with a greater perception of disease severity.

Under natural products, the differences between the two groups were statistically significant for the consumption of multivitamin, Korean black raspberry, ginseng and red ginseng, blood circulation supplement pills, and herbal tea. As for mind and body practices, the practice of lower body and hot spring bath was significantly higher in the high-perceived severity group. Among other complementary health approaches, the use of herbal medicine was significantly greater in the group with a higher rating of the perceived severity of the disease. Thus, significant differences in the pattern of CAM use found between the group with higher perceived severity and the lower perceived severity group were mostly in regards to using modalities with phytomedicinal properties (herbal medicine, herbal tea, Korean black raspberry, and ginseng) rather than simple manipulative practices. Although believed to be safe, the evidence for the effectiveness of CAM use is still inconclusive, and some of the natural products and herbal medicine may have a negative effect on infertile women undergoing hormone-sensitive therapies [41-44]. Therefore, physicians should pay attention to patients' use of CAM modalities during conventional treatment to prevent potential adverse effects when used in conjunction with conventional medical treatment, and additional studies should be conducted to ensure the safety and effectiveness of CAM modalities.

Differences in clinical and health-related characteristics of infertile women depending on the level of perceived disease severity were also observed in this study. Due to the financial and psychological burden which comes with treatment costs, social and cultural stigma, and emotional difficulties, notable consequences of infertility are anxiety, stress, and depression $[45,46]$. Our findings also show a higher level of self-perceived stress in the group with a greater perception of disease severity. Furthermore, the proportion of women with infertility treatment duration longer than 2 years was greater in higher-rating of disease severity group, and the number of women who have been diagnosed with infertility for longer than 2 years was also higher in the group with greater disease severity. Thus, these emotional stressors may have led the women to seek additional care outside of conventional medical care despite the lack of definitive effects of CAM modalities [41, 47, 48].

Potential predictors of CAM use established in our sample include non-employment, infertility treatment duration of 2-4 years, and self-perception of disease severity as severe. Previous studies found household income, age of the respondent, type of infertility treatment, duration of the marriage, education level, positive CAM attitudes as possible predictors of CAM use, yet our results displayed no congruency $[11,12,19,28]$.

Limitations of this study include recall bias and lack of variability in research locations. The participants were selected from three infertility clinics located in Seoul city; therefore, the views and opinions of study participants may not fully reflect those of the other infertile women. However, despite these limitations, this study is 
the first study to examine differences in types of CAM modalities used and the clinical characteristics of respondents by the perceived severity of the disease.

\section{Conclusions}

Our findings demonstrate that CAM use is common among infertile women in Korea. Those also highlight the association of CAM use with employment status and a reproductive health condition such as infertility treatment duration and self-perceived severity of infertility condition. Significant differences were also reported on the preferred method of CAM modalities between the group with a higher rating of self-perceived disease severity and lower perceived severity group. As such, infertile women's own understanding and perception of their illness and physical condition influence self-care behavior such as CAM use. To provide the best care to infertile women, physicians must be recommended to stay up to date with knowledge on CAM use and the safety of CAM modalities, specifically when used in conjunction with conventional treatment.

\section{Abbreviations}

CAM: Complementary and alternative medicine; IUI: Intrauterine insemination; IVF: In vitro fertilization

\section{Acknowledgments}

The authors would like to express their sincere gratitude to all the participants for their cooperation and willingness to share their experiences.

\section{Authors' contributions}

$\mathrm{JH}, \mathrm{HB}$, and DW were responsible for the study concept and design. DW, JH, and $\mathrm{HB}$ analyzed the data and drafted the manuscript. YY and DW contributed to the designing of data collection tools and data collection. $\mathrm{JH}$, $D W, H B$, and $Y Y$ critically reviewed the manuscript and contributed intellectual content. All authors read and approved the final manuscript.

\section{Funding}

None.

\section{Availability of data and materials}

The data will be accessible by contacting the corresponding author of this study.

\section{Ethics approval and consent to participate}

Ethical approval for the study was acquired from the Institutional Review Board on Human Subjects Research and Ethics Committees, Hanyang University (HYI-12-019). Enrollment of the respondents was voluntary, and all patients gave written consent to participate in the study.

\section{Consent for publication}

Not applicable.

\section{Competing interests}

The authors declare that they have no competing interests.

\section{Author details}

'Department of Obstetrics and Gynecology, Hanyang University College of Medicine, Seoul, South Korea. ${ }^{2}$ Department of Global Health and Development, Graduate school, Hanyang University, Seoul, South Korea. ${ }^{3}$ Institute of Health Services Management, Hanyang University, Seoul, South Korea. ${ }^{4}$ Graduate School of Public Policy, Hanyang University, Seoul, South Korea. ${ }^{5}$ Department of Preventive Medicine, Hanyang University College of Medicine, 222 Wangsimni-ro, Seongdong-gu, Seoul 04763, South Korea.
Received: 31 March 2019 Accepted: 23 October 2019

Published online: 06 November 2019

\section{References}

1. Complementary, Alternative, or Integrative Health: What's In a Name? https://nccih.nih.gov/health/integrativehealth. Accessed 20 Mar 2019.

2. Berretta M, Della Pepa C, Tralongo P, Fulvi A, Martellotta F, Lleshi A, Nasti G, Fisichella R, Romano C, De Divitiis C. Use of Complementary and alternative medicine (CAM) in cancer patients: an Italian multicenter survey. Oncotarget. 2017;8(15):24401.

3. Wieland LS, Manheimer E, Berman BM. Development and classification of an operational definition of complementary and alternative medicine for the Cochrane collaboration. Altern Ther Health Med. 2011;17(2):50.

4. Rayner J-A, Willis K, Burgess R. Women's use of complementary and alternative medicine for fertility enhancement: a review of the literature. J Altern Complement Med. 2011;17(8):685-90.

5. Smith CA, Bateson DJ, Weisberg E. A survey describing the use of complementary therapies and medicines by women attending a family planning clinic. BMC Complement Altern Med. 2013;13(1):224.

6. Rayner J-A, McLachlan HL, Forster DA, Cramer R. Australian women's use of complementary and alternative medicines to enhance fertility: exploring the experiences of women and practitioners. BMC Complement Altern Med. 2009;9(1):52

7. O'Reilly E, Sevigny M, Sabarre K-A, Phillips KP. Perspectives of complementary and alternative medicine (CAM) practitioners in the support and treatment of infertility. BMC Complement Altern Med. 2014;14(1):394.

8. Gaffney L, Smith CA. Use of complementary therapies in pregnancy: the perceptions of obstetricians and midwives in South Australia. Aust N Z Obstet Gynaecol. 2004;44(1):24-9.

9. Adams J, Lui CW, Sibbritt D, Broom A, Wardle J, Homer C, Beck S. Women's use of complementary and alternative medicine during pregnancy: a critical review of the literature. Birth. 2009;36(3):237-45.

10. Mascarenhas MN, Flaxman SR, Boerma T, Vanderpoel S, Stevens GA. National, regional, and global trends in infertility prevalence since 1990: a systematic analysis of 277 health surveys. PLoS Med. 2012:9(12):e1001356.

11. Smith JF, Eisenberg ML, Millstein SG, Nachtigall RD, Shindel AW, Wing H, Cedars M, Pasch L, Katz PP, Group IOPP. The use of complementary and alternative fertility treatment in couples seeking fertility care: data from a prospective cohort in the United States. Fertil Steril. 2010;93(7):2169-74.

12. Ghazeeri GS, Awwad JT, Alameddine M, Younes ZM, Naja F. Prevalence and determinants of complementary and alternative medicine use among infertile patients in Lebanon: a cross sectional study. BMC Complement Altern Med. 2012;12(1):129.

13. Kaadaaga HF, Ajeani J, Ononge S, Alele PE, Nakasujja N, Manabe YC, Kakaire $O$. Prevalence and factors associated with use of herbal medicine among women attending an infertility clinic in Uganda. BMC Complement Altern Med. 2014;14(1):27.

14. Hwang N. Curret status of physical, psychological, and socioeconomic burden of infertile women and their needs; 2011.

15. Choi M-S, Lee D-N, Kim D-I. A survey study on use condition of Korean medical institution and demand of Korean medical treatment project of infertility in infertile couple. J Orient Obstet Gynecol. 2013:26(2):151-65.

16. Luk BH-K, Loke AY. The impact of infertility on the psychological well-being, marital relationships, sexual relationships, and quality of life of couples: a systematic review. J Sex Marital Ther. 2015;41(6):610-25.

17. Patel M. The socioeconomic impact of infertility on women in developing countries. Facts Views Visi Obgyn. 2016;8(1):59.

18. Hwang $\mathrm{N}$, Jang I. Factors influencing the depression level of couples participating in the National Supporting Program for infertile couples. J Korean Acad Community Health Nurs. 2015;26(3):179-89.

19. James PB, Taidy-Leigh L, Bah AJ, Kanu JS, Kangbai JB, Sevalie S. Prevalence and correlates of herbal medicine use among women seeking Care for Infertility in Freetown, Sierra Leone. Evid Based Complement Alternat Med. 2018;2018:9493807.

20. Shannon J, El Saigh I, Tadrous R, Mocanu E, Loughrey J. Usage of herbal medications in patients undergoing IVF treatment in an Irish infertility treatment unit. Ir J Med Sci. 2010;179(1):63-5.

21. Coulson C, Jenkins J. Complementary and alternative medicine utilisation in NHS and private clinic settings: a United Kingdom survey of 400 infertility patients. J Exp Clin Assist Reprod. 2005;2(1):5. 
22. Bardaweel SK, Shehadeh M, Suaifan GA, Kilani M-VZ. Complementary and alternative medicine utilization by a sample of infertile couples in Jordan for infertility treatment: clinics-based survey. BMC Complement Altern Med. 2013;13(1):35

23. Stankiewicz M, Smith C, Alvino H, Norman R. The use of complementary medicine and therapies by patients attending a reproductive medicine unit in South Australia: a prospective survey. Aust N Z J Obstet Gynaecol. 2007; 47(2):145-9.

24. Hung Y-C, Kao C-W, Lin C-C, Liao Y-N, Wu B-Y, Hung I-L, Hu W-L. Chinese Herbal Products for Female Infertility in Taiwan: A Population-Based Cohort Study. Medicine. 2016;95(11):e3075

25. Edirne T, Arica SG, Gucuk S, Yildizhan R, Kolusari A, Adali E, Can M. Use of complementary and alternative medicines by a sample of Turkish women for infertility enhancement: a descriptive study. BMC Complement Altern Med. 2010;10(1):11.

26. Özkan FS, Karaca A, Sarak K. Complementary and alternative medicine used by infertile women in Turkey. Afr J Reprod Health. 2018;22(2):40-8.

27. Harris P, Cooper K, Relton C, Thomas K. Prevalence of complementary and alternative medicine (CAM) use by the general population: a systematic review and update. Int J Clin Pract. 2012;66(10):924-39.

28. Günay O, Cetinkaya F, Nacar M, Aydin T. Modern and traditional practices of Turkish infertile couples. Eur J Contracept Reprod Health Care. 2005;10(2): 105-10.

29. Rosenstock IM, Strecher VJ, Becker MH. Social learning theory and the health belief model. Health Educ Q. 1988;15(2):175-83.

30. Jung Hye Hwang, Woon-Yong Kim, Mansoor Ahmed, Soojeung Choi, Jiwoo Kim, and Dong Woon Han, "The Use of Complementary and Alternative Medicine by Korean Breast Cancer Women: Is It Associated with Severity of Symptoms?," Evidence-Based Complementary and Alternative Medicine. 2015;2015(Article ID 182475):7. https://doi.org/10.1155/2015/182475.

31. Ng T, Wong M, Hong C, Koh K, Goh L. The use of complementary and alternative medicine by asthma patients. Qjm. 2003;96(10):747-54.

32. Hollyer T, Boon H, Georgousis A, Smith M, Einarson A. The use of CAM by women suffering from nausea and vomiting during pregnancy. BMC Complement Altern Med. 2002;2(1):5.

33. van der Sluijs CP, Bensoussan A, Liyanage L, Shah S. Women's health during mid-life survey: the use of complementary and alternative medicine by symptomatic women transitioning through menopause in Sydney. Menopause. 2007;14(3):397-403.

34. Khetarpal A, Singh S. Infertility: why can't we classify this inability as disability? Australas Med J. 2012;5(6):334

35. Hwang NM, Moon SY, Kim TJ, Sim EH. A study on utilization of health services and coping strategies for infertility in Korea. Korea Institute for Health and Social Affairs \& Korea Health Promotion Foundation Management Center. 2003. Report No:2003-13.

36. Hwang NM, Hwang JH \& Kim JE. Evaluation of the national supporting program for infertility couples and future policy directions in Korea. Sejong: Korea Institute for Health and Social Affairs. 2010.

37. Yoon TY, Hwang JH, Han DW, Lee JE, Woo HK. Supporting strategy for infertility couple. Gwacheon: Ministry of Health and Welfare. 2006.

38. Vincent C, Furnham A. Why do patients turn to complementary medicine? An empirical study. Br J Clin Psychol. 1996;35(1):37-48.

39. Jo J, Kim T-H, Hyun MK, Kim H, Kim DI. Traditional Korean medicine for female infertility: a review of results from infertility support programs in Korea. Eur J Integr Med. 2016;8(5):847-53.

40. Heo J. Donguibogam, vol. 276. Seoul: Namsandang; 1994.

41. Boivin J, Schmidt L. Use of complementary and alternative medicines associated with a 30\% lower ongoing pregnancy/live birth rate during 12 months of fertility treatment. Hum Reprod. 2009;24(7):1626-31.

42. Ried K. Chinese herbal medicine for female infertility: an updated metaanalysis. Complement Ther Med. 2015;23(1):116-28.

43. Jiang D, Li L. Effect of Chinese Herbal Medicine on Female Infertility. Obstet Gynecol Int J. 2017;8(1):00274.

44. Miner SA, Robins S, Zhu YJ, Keeren K, Gu V, Read SC, Zelkowitz P. Evidence for the use of complementary and alternative medicines during fertility treatment: a scoping review. BMC Complement Altern Med. 2018;18(1):158.

45. Ramezanzadeh F, Aghssa MM, Abedinia N, Zayeri F, Khanafshar N, Jafarabadi M. Surveying of relationship between anxiety, depression and duration of infertility. In International Congress Series. Elsevier. 2004;1271:334-37).

46. Cwikel J, Gidron Y, Sheiner E. Psychological interactions with infertility among women. Eur J Obstet Gynecol Reprod Biol. 2004;117(2):126-31.
47. El-Toukhy $T$, Sunkara S, Khairy M, Dyer R, Khalaf Y, Coomarasamy A. A systematic review and meta-analysis of acupuncture in in vitro fertilisation. BJOG Int J Obstet Gynaecol. 2008;115(10):1203-13.

48. Cheong YC, Hung Yu Ng E, Ledger WL. Acupuncture and assisted conception. Cochrane Database Syst Rev. 2008;(4):CD006920. https://doi.org/ 10.1002/14651858.CD006920.pub2.

\section{Publisher's Note}

Springer Nature remains neutral with regard to jurisdictional claims in published maps and institutional affiliations.
Ready to submit your research? Choose BMC and benefit from:

- fast, convenient online submission

- thorough peer review by experienced researchers in your field

- rapid publication on acceptance

- support for research data, including large and complex data types

- gold Open Access which fosters wider collaboration and increased citations

- maximum visibility for your research: over $100 \mathrm{M}$ website views per year

At BMC, research is always in progress.

Learn more biomedcentral.com/submissions 